\title{
Gestão da mudança dos padrões culturais em direção ao paradigma da transformação: o caso da organização alfa
}

\author{
Nildes Pitombo Leite, $D r$. \\ Programa de Pós-Graduação da Faculdade de Economia, Administração e Contabilidade - FEA/USP \\ nildespitombo@consensopg.com.br \\ Vanderli Correia Prieto, Doutoranda \\ Programa de Pós-Graduação em Engenharia de Produção da Escola Politécnica da USP, Professora da \\ Universidade Presbiteriana Mackenzie / Depto. CCSA - Centro de Ciências Sociais Aplicadas. \\ vanderli.prieto@poli.usp.br
}

\begin{abstract}
Este trabalho aborda o estudo do processo de mudança dos padrões culturais de uma subsidiária, no Brasil, de uma organização multinacional norte-americana que produz insumos para a indústria de aço. Adotou-se o modelo teórico de processo de transformação de quatro etapas, envolvendo auscultação, concepção, disseminação e sustentação. A pesquisa de campo desenvolveu-se por meio de um estudo de caso de natureza exploratória. Utilizou-se o método qualitativo de coleta e análise dos dados. Envolveram-se, na coleta, cinco grupos de mobilização, constituídos com base nos incidentes críticos levantados pela organização, totalizando sessenta e oito pessoas. Buscou-se responder a questão de pesquisa: Como gerir o processo de mudança dos padrões culturais de uma organização, do paradigma da estabilidade para o da transformação? A partir das análises realizadas, pôde-se concluir que a forma de gerir o processo de mudança dos padrões culturais da organização Alfa encontra resposta no próprio processo estratégico de transformação utilizado, que buscou desenvolver a interação contínua e a regulação entre contexto, processo e conteúdo.
\end{abstract}

Palavras-chave: gestão de mudança, cultura organizacional, paradigma da transformação

This study refers to the change process the cultural pattern of a Brazilian subsidiary of an American-based multinational company that produces inputs for the steel industry. The theoretical transformation process model adopted encompasses four phases: diagnosis, conception, dissemination, and maintenance. The field research was developed through an exploratory case study. Qualitative methodology for data collection and analysis was applied. Five mobilization groups, formed in accordance with the critical incidents noticed by the company, a total of sixtyeight persons, took part of the data collection. The aim of the study is to answer the research question How to manage the cultural pattern change process of an organization, from the stability paradigm toward one of transformation? Analyses led to the conclusion that the answer to this question lies on the very strategic transformation process adopted, encompassing content, context and process and its interactions.

Keywords: change management, organizational culture, transformation paradigm

\section{Introdução}

Por que será que indivíduos, nações e culturas experienciam sobressaltos como o terrorismo, a confusão, o desmoronamento de governos e de instituições? Dever-se-á a numerosas mudanças de paradigmas que estão ocorrendo simultaneamente? O que vem a ser uma mudança de paradigma?

Numa certa época foi perfeitamente claro que se vivia em um mundo plano, no qual o homem era o centro do universo e o sol, as estrelas, os planetas giravam em torno dele. Alguns pensadores não ortodoxos e 
heréticos, dos quais Copérnico é o símbolo, desenvolveram então um padrão completamente novo. A Terra seria uma esfera girando ao redor do sol, uma pequena parte de uma enorme galáxia que incluía os planetas e outros objetos estrelares. As pessoas foram confrontadas com a possibilidade de que o primeiro paradigma estava enormemente errado e existiria um modo inteiramente novo de perceber o universo. Tiveram elas de enfrentar a possibilidade de mudar de um paradigma para outro.

Desse modo, naquela época, muitos continuaram a viver num mundo plano, zombando das novas concepções. Qualquer que seja a época, há uma visão do mundo que é aceita de um modo geral. Um padrão, por meio do qual, tanto os cientistas como os leigos extraem sentido da realidade tal como ela é percebida. Assim também ocorre com os padrões organizacionais. O padrão organizacional relembrado por Helliwell (2002:242) diz que

\begin{abstract}
as empresas do estilo antigo valorizavam seus empregados e cuidavam deles, assegurando-lhes emprego por um longo período - muitas vezes, pela vida inteira - se trabalhassem direito. Com maior freqüência, os líderes eram empregados de carreira, que percorriam toda a escala hierárquica e assim conheciam seus subordinados como indivíduos. Então, esses líderes ajudavam a criar um tipo de ambiente de trabalho familiar [...] Embora já não sejam capazes de assegurar emprego de longo prazo, as empresas podem garantir que seus empregados sejam tratados com justiça e respeito e que tenham oportunidades para desenvolver o coração e a mente no trabalho.
\end{abstract}

Tal padrão demonstra que aqueles que tinham a mente aberta começaram a viver o novo paradigma. Essa mudança no modo de ver o mundo transformou não apenas a percepção do homem acerca da cosmologia, mas a percepção do lugar do homem no universo.

A inteligência não consciente desse homem parece estar ganhando tanto uma nova consciência de sua força e poder, quanto o reconhecimento de que a única coisa constante na vida é o processo de mudança. A implicação desse reconhecimento é que as organizações vivem atualmente a polarização entre padrões passados e futuros de identidade em processos de mudança organizacional. Novamente é trazida a contribuição de Helliwell (2002:270), dessa feita com a afirmação de que "as empresas visionárias estão abrindo mão das visões antigas e criando tempo e espaço para que surjam visões novas para elas e seus empregados”. Esse tempo, criado pela necessidade de conhecer e controlar, é também determinante para o permanente processo de mudança.

É dentro desses padrões passados e futuros que se inserem os paradigmas da estabilidade e da transformação. Elucidados por Fischer (2002), esses paradigmas podem ser assim resumidos: muito embora o paradigma da estabilidade não negue que as organizações estão em mudança constante, pressupõe que as alterações possam ser sempre harmônicas, sutis e incrementais, sem que desestabilizem o desempenho organizacional; o paradigma da transformação pressupõe que o esforço de mudança seja concebido como estratégia de ação voltada para o aperfeiçoamento contínuo.

O modelo de gestão de pessoas, requerido para esses processos de transformação de padrões, não poderá mais restringir-se ao caráter instrumental, mas deverá sistematizar componentes políticos, ideológicos, sociais e comportamentais que orientem a ação e a decisão no contexto organizacional. Isso significa mudança nos padrões culturais com implicações no processo de transformação. Nesse sentido, Duck (1999:66) afirma:

Para que os empregados contribuam com a mente e o coração as empresas precisam aceitar que as emoções são essenciais ao novo estilo gerencial. O velho paradigma gerencial pregava que no trabalho as pessoas só deveriam sentir emoções facilmente controláveis [...] O novo paradigma gerencial ensina que gerenciar pessoas é gerenciar sentimentos.

O padrão operacional no contexto organizacional evita emoções. A mudança desse padrão não é fácil e um dos paradoxos de tal mudança é a constatação de que a confiança é tão necessária quanto difícil de ser conquistada, de acordo com a literatura consultada. 
O presente trabalho trata do estudo do processo de transformação da Organização Alfa, uma empresa multinacional do setor industrial, tomando-se por base os elementos facilitadores e dificultadores desse processo. Considerando-se as diretrizes teóricas adotadas, os objetivos da pesquisa podem ser assim elucidados: explicitar a forma de gestão da mudança dos padrões culturais, em processo de transformação, da organização escolhida, identificar os fatores que facilitam ou dificultam a gestão da mudança dos seus padrões culturais e caracterizar o seu ambiente interno (cultura organizacional). A partir de então, a questão de pesquisa formulada é: Como gerir o processo de mudança dos padrões culturais de uma organização?

Justificam a escolha da fundamentação, neste trabalho, alguns pressupostos teóricos de mudança organizacional, quais sejam: muitas organizações têm caráter não-linear e encaram a estabilidade como nociva à evolução (KIEL, 1989); as mudanças são, necessariamente, acompanhadas por quebras de paradigmas (HUEY, 1991); mudança organizacional engloba alterações fundamentais no comportamento humano, nos padrões de trabalho e nos valores, a mudança ocorre em resposta a modificações ou antecipações estratégicas, tecnológicas ou de recursos (HERZOG, 1991).

\section{Fundamentação Teórica}

A fundamentação teórica foi desenvolvida a partir dos seguintes termos considerados relevantes para o estudo: mudança, cultura e transformação. Esses termos são aqui seqüencialmente tratados.

\subsection{Mudança}

Para os filósofos, ressaltados por Abbagnanno (2003), a mudança é entendida como o movimento ou a realização do que está em potência, a exemplo da construção, da aprendizagem, da cura, do crescimento, do envelhecimento.

Na operacionalização desses pressupostos, os desafios da liderança perpassam as habilidades de lidar com o processo de mudança organizacional, iniciando pela revisão dos papéis - de controlador para facilitador - assim como pela revisão das estratégias - de controle da disciplina para comprometimento com o trabalho. Isso requer coragem e disposição. Para Martin (1999:130) “é impossível mudar a organização sem coragem e não há como induzir a coragem de cima para baixo, nem com base em exemplos. No entanto, é possível tornar as metas e métodos bastante transparentes para que os empregados se disponham a assumir riscos calculados”.

Historicamente, até a década de 70 o processo de mudança organizacional refletia a visão de controle, como função mais importante, e o asseguramento da capacidade de reprodução de rotinas e procedimentos. Esse processo era visto, sobretudo, como um projeto isolado e esporádico, instaurador de alterações pontuais em algum aspecto da estrutura ou em alguma etapa do processo tão-somente. Até então, a mudança era considerada como um fenômeno de difícil administração.

A partir dessa década, a modificação gradativa dessa visão reconduziu as organizações para modelos de gestão, nos quais a mudança organizacional passou a ser conceituada, concebida e gerenciada como um processo contínuo de transformação, conforme explicitado por Fischer (2002). Essa visão de processo de transformação vem exigindo que o gestor desempenhe o papel de facilitador de condições para o desenvolvimento permanente.

Em relato de observações de esforço de mudança, Kotter (1999) chama a atenção de que nos casos de maior êxito, a lição genérica demonstra que o processo de mudança envolve uma série de fases e um tempo considerável. O autor diz ainda que a ilusão de velocidade criada pela eliminação de qualquer fase 
produz resultados insatisfatórios, assim como erros críticos em algumas delas podem exercer impacto devastador.

Com base nesse autor, a transformação organizacional exige do papel das lideranças: atenção à dificuldade de retirar as pessoas das suas zonas de conforto; papel de apoio ativo do chefe da organização; clareza e comunicação da visão; remoção dos possíveis entraves à estrutura organizacional; manutenção da coerência entre o discurso e a prática, por parte dos gestores do processo; enfrentamento e remoção dos obstáculos; celebração das metas de curto prazo, efetivamente alcançadas durante o processo; ancoragem das mudanças na cultura organizacional. Essa visão do papel das lideranças na transformação organizacional apresenta-se como um processo perfeito, portanto, fadado ao inatingível, considerando-se as limitações e imperfeições humanas dos gestores organizacionais.

Entretanto, essas exigências encontram eco entre estudiosos e estão alinhadas com o pensamento de Duck (1999). Ele enfatiza que a gestão da mudança difere de qualquer outra tarefa gerencial com que a maioria dos executivos já se defrontou, pois, como tarefa crítica, consiste em compreender como todos os componentes da mudança se equilibram entre si, como a alteração de um elemento afeta o estado de repouso e como a sequenciação e o ritmo impactam toda a estrutura. Novamente, aqui se depara com uma tendência à perfeição, uma excelsa capacidade de atenção concentrada ao nível da interdependência e a lembrança de que a gestão continua sendo um processo de pessoas com pessoas, portanto, passível de imperfeições.

Ainda de acordo com Duck (1999), a espiral desses processos de mudança tem início com a visão corporativa que exija mudança de atitude e, em conseqüência, contribua para a mudança de comportamento, a qual possa resultar na melhoria do desempenho organizacional. A constatação dos resultados positivos, por sua vez, implicará no comprometimento com o esforço da mudança organizacional e é essa constatação que dá continuidade à espiral.

Por outro lado, Schaffer e Thompson (1999) advogam que tanto a sobrevivência quanto a prosperidade da organização dependem das difíceis decisões estratégicas de responsabilidade da gerência sênior. Os programas de melhoria à base de resultados não atenuam tal responsabilidade. Os autores afirmam que a associação dos objetivos estratégicos, de longo prazo, com os projetos de melhoria de curto prazo capacita a gerência na conversão da trajetória estratégica em realidade. Esses autores enfatizam que a gerência necessita reconhecer a abundância na organização, tanto de capacidades como de dissipação de recursos. Ainda que difícil, esse processo de reconhecimento é tão mais factível quanto desenvolvida a sensibilidade dos gestores para tal.

Os estudiosos, até aqui mencionados, registram que os ventos das mudanças científica, social e cultural parecem estar soprando fortemente. As enormes perturbações da sociedade moderna, provavelmente forçarão uma transformação para uma ordem nova e mais coerente, em que uma necessidade de interdependência entre as organizações e a sociedade será ressaltada. Em conseqüência, o processo dialético de construção-desconstrução que constitui a evolução conjunta desses dois níveis em uma interestruturação constante, baseada em interações contínuas, talvez também possa vir a ser ressaltado.

\subsection{Cultura}

Na perspectiva da antropologia, a cultura é um conjunto de padrões de comportamento, crenças, conhecimentos e costumes que distinguem um grupo social. A contracultura mostra a forma ou etapa evolutiva das tradições e valores intelectuais, morais, espirituais, de um lugar ou período específico. Abbagnano (2003) diz que para os gregos, a cultura foi a busca e a realização que o homem faz de si, da verdadeira natureza humana, constituindo-se de dois caracteres: o primeiro consiste na estreita conexão 
com a filosofia, na qual se incluíam todas as formas de investigação; o segundo implica em estreita conexão com a vida social.

A antropologia registrou, nos últimos anos, de acordo com Dupius (1996:232) “uma penetração notável no campo das ciências da organização. A popularidade do conceito de 'cultura' - conceito central da antropologia - no tratamento das realidades organizacionais atesta este fato”.

Na comunhão da antropologia e da sociologia, a cultura pode ser expressa por um conjunto de atitudes, linguagens, conhecimentos e costumes, explícita ou implicitamente difundidos e estimulados pelos meios de comunicação, mantidos ou utilizados pelo Estado e suas autoridades constituídas. Ainda nessa comunhão, pode ser vista como um conjunto de conhecimentos acumulados e socialmente valorizados, que constituem patrimônio da sociedade.

A gestão de cultura é um dos aspectos ligados às dimensões humanas. Mudar a maneira de interagir significa reprojetar, não apenas as estruturas formais da organização, mas os padrões de interação entre pessoas e processos. A mudança de cultura de uma organização implica em uma necessidade de revisão dos valores que a norteiam. O alerta que é dado por Pettigrew (1989), além de envolver a interpelação dos problemas que tornam a cultura organizacional difícil de ser gerenciada e, mais ainda, de ser modificada, dá a dose necessária do realismo para se compreender a complexidade dos processos de mudança.

Com a finalidade de dialogar com alguns autores têm-se, no Quadro 1, alguns conceitos de cultura e possíveis entrelaçamentos entre eles.

\begin{tabular}{|c|c|c|}
\hline Autores & Conceitos/Abordagens & Pontos Explorados \\
\hline $\begin{array}{l}\text { Aktouf } \\
\text { (2001:49) }\end{array}$ & $\begin{array}{l}\text { "a cultura é um conjunto complexo e multidimensional } \\
\text { de praticamente tudo o que constitui a vida em comum } \\
\text { nos grupos sociais". } \\
\text { "As aparências de comunidade não são a comunidade, } \\
\text { as palavras da cultura não são a cultura. A } \\
\text { imaterialidade simbólica e representacional devem } \\
\text { estar ancoradas em sua materialidade inscrita nas } \\
\text { estruturas, na experiência vivida e nas práticas sociais } \\
\text { da empresa; esta materialidade mantém, } \\
\text { necessariamente, uma relação de anterioridade com a } \\
\text { imaterialidade". }\end{array}$ & $\begin{array}{l}\text { O autor partiu de um foco abrangente, com a } \\
\text { amplitude da cultura voltada para a sociedade. } \\
\text { Observa-se que o seu foco é trazido para a } \\
\text { questão da materialidade e imaterialidade nas } \\
\text { práticas sociais da organização, o que relembra } \\
\text { a necessidade de atenção para a confluência dos } \\
\text { aspectos lineares e não-lineares que envolvem } \\
\text { as transformações. }\end{array}$ \\
\hline $\begin{array}{l}\text { Schein } \\
(1985: 9)\end{array}$ & $\begin{array}{l}\text { "cultura organizacional é o conjunto de pressupostos } \\
\text { básicos que um grupo inventou, descobriu ou } \\
\text { desenvolveu ao aprender como lidar com os problemas } \\
\text { de adaptação externa e integração interna e que } \\
\text { funcionaram bem o suficiente para serem considerados } \\
\text { válidos e ensinados a novos membros como a forma } \\
\text { correta de perceber, pensar e sentir, em relação a esses } \\
\text { problemas". }\end{array}$ & $\begin{array}{l}\text { Aqui, o foco recai no grupo que pode ser } \\
\text { encontrado dentro de qualquer organização, em } \\
\text { relação aos problemas culturais que podem } \\
\text { envolver adaptação e integração organiza- } \\
\text { cional. }\end{array}$ \\
\hline $\begin{array}{l}\text { Fleury e } \\
\text { Sampaio } \\
(2002: 293)\end{array}$ & $\begin{array}{l}\text { “cultura organizacional é o conjunto de valores e } \\
\text { pressupostos básicos expresso em elementos } \\
\text { simbólicos que, em sua capacidade de ordenar, atribuir } \\
\text { significações, construir a identidade organizacional, } \\
\text { tanto agem como elemento de comunicação e } \\
\text { consenso, como ocultam e instrumentalizam as } \\
\text { relações de dominação”. }\end{array}$ & $\begin{array}{l}\text { Nessa definição, observe-se a inserção do } \\
\text { poder, ainda não presente no conceito de } \\
\text { cultura expresso pos Schein. }\end{array}$ \\
\hline $\begin{array}{l}\text { Silva } \quad \text { e } \\
\text { Zanelli } \\
(2004: 413)\end{array}$ & $\begin{array}{l}\text { "a cultura é compreendida como um instrumento que } \\
\text { regula e adapta pessoas e organizações [...] outra idéia } \\
\text { subjacente é a de que o controle e o aumento da }\end{array}$ & $\begin{array}{l}\text { Nesse ponto, o foco reforça o elemento do } \\
\text { poder e desperta para uma possibilidade de } \\
\text { transformação na forma de gestão, na qual }\end{array}$ \\
\hline
\end{tabular}




\begin{tabular}{|c|c|c|}
\hline & $\begin{array}{l}\text { produtividade, além do uso adequado de técnicas, } \\
\text { ocorreriam se os dirigentes compreendessem o } \\
\text { comportamento, as expectativas, os pensamentos e os } \\
\text { sentimentos dos funcionários". }\end{array}$ & $\begin{array}{l}\text { gestores e integrantes da equipe organizacional } \\
\text { tendem a partilhar a aprendizagem no processo } \\
\text { de mudança cultural. No entanto, a } \\
\text { complexidade dessa aprendizagem reside na } \\
\text { impossibilidade de prescrições de receita ou } \\
\text { fórmula para variadas situações, exigindo do } \\
\text { pesquisador e do profissional o depuramento do } \\
\text { seu instrumental conceitual e de diagnose, } \\
\text { quando do trato de desenvolvimento de uma } \\
\text { cultura que pressupõe comprometimento dos } \\
\text { empregados com os objetivos organizacionais. }\end{array}$ \\
\hline $\begin{array}{l}\text { Amado, } \\
\text { Faucheux e } \\
\text { Laurent } \\
\text { (2001) }\end{array}$ & $\begin{array}{l}\text { Chamam a atenção para o fato de que o complexo } \\
\text { domínio das realidades culturais sobre os constructos } \\
\text { organizacionais reclama, talvez, o desenvolvimento de } \\
\text { uma capacidade para exorcizar as culturas a fim de } \\
\text { evitar a dupla armadilha do relativismo cultural e } \\
\text { asséptico e da cegueira cultural inconsciente. }\end{array}$ & $\begin{array}{l}\text { Para os autores essa capacidade permitiria, } \\
\text { então, simultaneamente, uma integração } \\
\text { criadora das realidades culturais e sua } \\
\text { superação. }\end{array}$ \\
\hline \multicolumn{3}{|c|}{$\begin{array}{c}\text { Quadro } 1 \text { - Conceitos de Cultura e Pontos Explorados } \\
\text { Fonte: Elaborado pelas autoras a partir da literatura consultada }\end{array}$} \\
\hline
\end{tabular}

O debate de como os padrões culturais, dominantes em uma organização, podem dificultar os processos de aprendizagem e mudança, principalmente quando os desafios que se estabelecem são o de desaprender e aprender novamente, está presente no mundo dos pesquisadores e das organizações que estão voltadas para a aprendizagem.

Um dos grandes desafios da gestão da cultura diz respeito aos caminhos que devem ser seguidos para a transformação cultural. A complexidade, inerente à transformação, não pode ser ignorada, qualquer que seja o caminho escolhido.

De acordo com Chanlat (1996:35), "os seres humanos constroem, destroem e reconstroem sua realidade, a partir de experiências ao mesmo tempo antigas e novas: a transformação de uma cultura é um modo de sua reprodução”.

Dentre os pressupostos básicos que envolvem a concepção e a implementação de um processo contínuo de mudança destaca-se o que sugere que as mudanças acontecem como processos inerentes à dinâmica das organizações e às estratégias de ação por elas definidas.

Para este trabalho é assumido o pressuposto teórico de que "uma forte cultura pressupõe o comprometimento dos empregados com os objetivos organizacionais” (FLEURY e FLEURY, 1997).

É assumido, ainda, que "o alinhamento entre as declarações da empresa e o comportamento gerencial é a chave para a construção de um contexto que promova o comprometimento dos empregados na dimensão social” (STREBEL, 1999).

\subsection{Transformação}

Sob a ótica da filosofia, Abbagnano (2003) elucida que o conceito de transformação engloba a categoria fundamental do raciocínio matemático, segundo o qual o conteúdo consiste em possibilidades que exigem a formulação em símbolos.

Como poderão as organizações transformar as suas formas de administrar?

A transformação organizacional é iniciada quando há a compreensão clara das situações que a facilitam ou a obstam, quais sejam: se os líderes valorizam a qualidade de vida, as equipes tendem a sentirem-se sólidas e eficazes, promovendo a multiplicação; se eles se encontram divididos, as equipes tendem a 
conhecer as limitações e ficam a mercê do aproveitamento inteligente das brechas; se a cúpula se apresentar desunida e alheia ao cotidiano organizacional, as equipes tendem a sentirem-se incapazes, correndo o risco da dissolução.

É enfatizado por Adizes (1991) que a transformação tem como bases a aceitação da realidade e a movimentação em direção ao futuro. A transformação organizacional só é efetivamente conquistada com as pessoas, para as pessoas e por intermédio do envolvimento e do comprometimento das pessoas, o que necessita uma visão de mundo revolucionado, na qual a pessoa seja compreendida dentro da sua totalidade. Nesse sentido, Damásio (1996) contribui ao apontar a importância de esclarecer que a aprendizagem para a transformação envolve a dimensão emocional tanto quanto a dimensão mental, portanto, tendendo à totalidade humana.

A habilidade para viver nesse mundo organizacional transformado é marcada por certas características como: empenho no sentido de uma totalidade de vida, experienciando o pensamento, o sentimento, a energia física e a energia psíquica, de uma forma integrada; abertura para o mundo, tanto interior como exterior; tendência à descentralização da liderança compartilhando o poder; fomento ao crescimento, à criatividade, à cooperação, à transformação e à sinergia no processo grupal.

Wheatley (1992:28-29) afirma que,

o novo conceito de organização está se afastando das criações mecanicistas que floresceram na era da burocracia.
Começamos a falar a sério de estruturas mais fluídas e orgânicas, e até mesmo de organizações sem fronteiras.
Começamos a reconhecer as organizações como sistemas, concebendo-as como 'organizações de aprendizagem',
creditando-lhes algum tipo de capacidade de auto-renovação. À medida que deixamos de lado os modelos
mecanicistas de trabalho, começamos a dar um passo atrás e a ver a nós mesmos de novas maneiras, a apreciar a
totalidade que somos e a planejar organizações que honrem e façam uso dessa totalidade.

Os aperfeiçoamentos requeridos para que um processo de transformação organizacional ocorra são essencialmente focados em: revisão da estrutura organizacional, na qual as competências são explicitadas, as relações de autoridade e subordinação são estabelecidas, os canais formais de comunicação e decisão são clarificados; modelo de gestão propiciador de condições de decisão compartilhada e de ação focada em resultado e otimização do uso de recursos.

A possibilidade de transformação, vislumbrada por Rogers (1977), vigorará apenas se o ponto de partida estiver focado na visão das realidades divergentes como sendo a fonte mais promissora de aprendizagem. Para esse autor, quando os gestores delegam autoridade àqueles que executam o trabalho, acontece uma coisa extraordinária - as pessoas ficam à altura da responsabilidade e tomam decisões excelentes.

Assumindo como premissa que a transformação nas organizações só será possível a partir dos desejos mais profundos e conscientes dos seus integrantes, a transformação das equipes organizacionais reforça as necessidades de abertura, ajuda, efetividade para a solução dos problemas, comprometimento para o sucesso da implementação das decisões acerca do negócio, transformações na organização humana do trabalho, feedback, minimização da necessidade de competição, diminuição do número e da gravidade dos problemas entre liderados e líderes, incremento do nível de confiança e ambiente no qual autoridade e responsabilidade são bem redefinidos e redistribuídos.

A necessidade da compreensão do indivíduo, enquanto foco inicial de toda transformação para tomar por base as ações de acreditar na transformação, decidir transformar e reaprender continuamente é reforçada por Buscaglia (1994).

Direção, comando e hegemonia são significados ligados ao paradigma da estabilidade organizacional. À luz do paradigma transformacional, a lição mais difícil para muitos gestores é que, basicamente, não há 
nada que se possa fazer para se conseguir engajamento e participação de outra pessoa. Engajamento e participação exigem liberdade de escolha. Para Vasconcelos e Vasconcelos (2004), o modelo transformacional de gestão de pessoas coloca em questão a harmonia individual e a harmonia social.

As organizações que buscam transformar o modo de ver o mundo, não só se transformam em organizações sinérgicas, como se tornam capazes de produzir conhecimento, ao invés de reproduzi-lo apenas, baseadas na observação do homem enquanto ser integral. Em conseqüência, tornam-se competitivas e competentes, pois: aprendem a lidar com a sua complexidade; compreendem a empregabilidade como construção responsável, social, evolutiva e dinâmica que assegura aos indivíduos, substantivamente, os direitos à qualidade de vida e do trabalho; fomentam a importância da leitura como transmissora e formadora de aprendizagem e inteligência; repensam a educação para o trabalho, de modo interessante e desafiador; reconhecem a capacidade, a competência e a prontidão dos seres humanos nas ações de construir, destruir e reconstruir sua realidade a partir de experiências ao mesmo tempo antigas e novas; encaram a possibilidade de ensejar o exercício da empatia em toda a sua complexidade.

Esse processo de transformação organizacional já está acontecendo, há algumas décadas, de acordo com Moscovici (1994), e seus prenúncios podem ser percebidos em vários aspectos. Entretanto, para a autora, romper com modelos burocráticos, revisar sistema de crenças e valores e empreender ações facilitadoras de transformações em bases fundamentais constituem-se tarefas árduas para muitos integrantes das equipes organizacionais. Dentre esses integrantes figuram, principal e decisivamente, no processo de transformação organizacional os líderes de equipes funcionais que compõem o corpo gerencial e, por isso, responsáveis pelo repasse do modelo de atuação, portadores legítimos de influências marcantes na cultura organizacional ainda de acordo com essa autora. Ela demonstra o quanto o desenvolvimento de equipes pode constituir-se instrumento de transformação cultural das organizações, uma vez que está alicerçado em transformações significativas, em níveis intrapessoais, interpessoais, intragrupais, intergrupais, não só de conhecimentos, como de sentimentos, atitudes, valores, motivação, postura, comportamento.

Por fim, Moscovici (1994) considera que a transformação organizacional pressupõe maior espaço para a imaginação, a criatividade, a antevisão de resultados, em igualdade de importância com os conteúdos lineares. Para ela, encontrar o caminho, de forma singular e própria, com os recursos interiores, conduz à redescoberta com o ser, ao mesmo tempo, um todo singular e uma parte genérica interligada, conforme elucidado por Chanlat (1996).

Compreender melhor a natureza da organização pela decodificação da lógica de transformação e de mudança é a proposição de Morgan (1996), o qual enumera como imagens da mudança: as organizações enquanto sistemas que se auto-reproduzem (biologia); a lógica da mudança se acha encoberta pelas tensões e tendências encontradas nas relações circulares (cibernética); a mudança é produto das relações dialéticas entre opostos. O autor defende a idéia de que as organizações devem dedicar considerável atenção para descobrir e desenvolver um apropriado senso de identidade. A cultura organizacional deve ser sempre desenvolvida tomando-se por base essa abordagem da identidade, uma vez que a autoimagem de uma organização é crítica para moldar quase todos os aspectos do seu funcionamento e, em particular, o seu impacto no contexto do qual faz parte.

Perguntas como: Por onde começar uma iniciativa de mudança? Como dimensionar o grau de aceitação à intervenção nos diferentes níveis organizacionais? Em que seqüência o processo de intervenção deveria fluir? Como sustentar o processo de mudança? Podem orientar, mas não se propõem a esgotar a abordagem da gestão da mudança dos padrões culturais em processo de transformação, dada a complexidade nela envolvida. 
Na visão de autores como Fischer (2002) e Garvin (1998), nas organizações modernas a mudança é um dos processos organizacionais no qual está imbuída a idéia de continuidade, inerente, portanto, ao paradigma da transformação. Esses autores vêem a mudança como um processo que pode ser modelado e gerenciado.

Na opinião de Pettigrew (1989), o processo de mudança deve desenvolver a interação contínua e a regulação entre contexto, processo e conteúdo. O conteúdo representa a estratégia e as áreas específicas de mudança que são definidas considerando-se o contexto, representado pelo ambiente organizacional externo e interno; o processo de mudança diz respeito às ações, reações e interações que são desenvolvidas, buscando alterar o estágio atual da organização tendo em vista o futuro. O autor sugere que a articulação do processo de mudança, tanto da estratégia quanto da cultura organizacional, deve buscar a interação desses três aspectos organizacionais, buscando responder as questões 'o que mudar' (conteúdo), 'o por que mudar' (contexto) e 'o como mudar' (análise do processo). De acordo com a concepção de Chaves, Santos e Morais (2004), 'o por que' mudar pode ser classificado em reativo ou voluntário, 'o como mudar' em re-educativo ou coercitivo e 'o que mudar' em incremental ou revolucionário.

Fischer (ob. cit) assume essa articulação como um pressuposto para a mudança, representado por duas engrenagens: a do direcionamento estratégico (por que mudar) e a da configuração organizacional (o que mudar), a qual se traduz no sistema de gestão da organização. Ambas agem de maneira interdependente no processo de alavancar a competitividade organizacional. Quanto ao processo de transformação organizacional (como mudar), a autora define que ele deve ser ancorado pelos parâmetros de abrangência, integração e sustentação. A metodologia empregada na concepção e implementação do processo de transformação organizacional é sintetizada em um modelo de quatro etapas interdependentes e não necessariamente seqüenciais: auscultação, concepção, disseminação e sustentação.

Na etapa de auscultação realizam-se os levantamentos e as análises de dados que ajudam a identificar as características dos processos de trabalho, os fluxos de comunicação e a interação entre as diferentes áreas organizacionais. Tem o objetivo de determinar os aspectos impulsionadores e restritivos dos sistemas de gestão e dos resultados atuais da organização.

No processo de concepção dá-se a idealização do processo de mudança, incluindo a revisão das diretrizes estratégicas, mobilização de pessoas, definição de planos de ação até a concepção da disseminação.

Com a etapa de disseminação/adesão, o processo amplia-se para todos os atores da organização, em eventos estruturados, visando alcançar os objetivos propostos com a adesão consciente dos participantes. Sistemas de avaliação do desempenho organizacional podem auxiliar na aferição dos resultados.

A etapa de sustentação envolve um conjunto de atividades com o propósito de efetuar o monitoramento e a avaliação das ações e do rumo do processo. A auscultação deve ser permanente, visando o aperfeiçoamento contínuo.

\section{Procedimentos Metodológicos: Coleta e Análise dos Dados}

Com o propósito de responder à questão de pesquisa estabelecida neste trabalho utilizou-se o método qualitativo de coleta e análise dos dados, cujo emprego justifica-se pela compatibilidade com o tema proposto. A pesquisa qualitativa permite analisar aspectos subjetivos, como percepções, compreensão 
do contexto organizacional e dinâmica das interações grupais por intermédio de seus significados para as pessoas (RICHARDSON, 1989).

A abordagem qualitativa também está relacionada com o âmbito interno da organização, uma vez que, até certo ponto, as estruturas podem ser consideradas como estáticas. A pesquisa foi caracterizada como do tipo exploratória e descrita como estudo de caso. Muitas características do estudo de caso são semelhantes às da pesquisa qualitativa, o que pode evidenciar a relação de adequação do emprego de ambos. O estudo de caso, além de contar com muitas das técnicas utilizadas pelas pesquisas históricas, acrescenta duas fontes de evidências: observação direta dos acontecimentos que estão sendo estudados e entrevistas com pessoas neles envolvidas (YIN, 2005).

Os dados foram coletados em uma organização multinacional norte-americana que atua no setor de alta tecnologia fabril, produzindo insumos para a indústria de aço. Envolveram-se nessa coleta sessenta e oito pessoas, assim distribuídas: sete gerentes do grupo de refugos (considerados os gerentes de primeira linha), mais o diretor de produção, e o diretor de marketing; trinta integrantes do grupo de incidentes e acidentes (vinte e sete operadores que já haviam vivenciado a situação de acidentes, mais dois engenheiros de segurança e o diretor financeiro); no grupo do market share, quatorze envolvidos (sete integrantes da equipe de marketing e os sete gerentes representantes das demais áreas, também integrantes do grupo de refugos); oito membros do grupo de satisfação dos subordinados (seis gerentes de segunda linha, mais o diretor administrativo e o médico do trabalho); quatorze componentes do grupo de confiança (doze engenheiros, mais o diretor de tecnologia e o diretor presidente).

Por razões de preservação, a real identidade da organização foi omitida e ficou aqui referenciada como organização Alfa, conforme acordado com os dirigentes, gestores e pesquisadores. A seleção da empresa se deu em razão do contexto de mudança no qual está inserida, que caracteriza a transição do paradigma da estabilidade para o da transformação. Seu contexto é de alta competitividade, com poucos players ameaçados por muitos entrantes nos últimos anos. Os clientes estão cada vez mais consolidados e pressionam por redução de preços. A empresa apresenta incidentes críticos que remetem à perda de produtividade e de market share que, entende-se, não podem ser solucionados sem que haja a mudança dos padrões culturais. No Brasil, emprega um total de quatrocentos e noventa e duas pessoas e os cargos de direção são ocupados por engenheiros.

O processo de intervenção na organização seguiu as etapas do modelo de processo de transformação proposto por Fischer (2002) e relatado ao final da fundamentação teórica, envolvendo: auscultação, concepção, disseminação e sustentação. A articulação do processo de mudança da cultura organizacional foi construída buscando responder às questões: 'o que mudar' (conteúdo), ‘o por que mudar’ (contexto) e 'o como mudar’ (análise do processo) - seção 2.3. da Fundamentação Teórica.

Elucidados por essa autora, esses paradigmas podem ser assim resumidos: muito embora o paradigma da estabilidade não negue que as organizações estão em mudança constante, pressupõe que as alterações possam ser sempre harmônicas, sutis e incrementais, sem que desestabilizem o desempenho organizacional; o paradigma da transformação pressupõe que o esforço de mudança seja concebido como estratégia de ação voltada para o aperfeiçoamento contínuo.

A técnica básica de investigação foi a entrevista semi-estruturada, a qual, de acordo com Selltiz et al. (2005:40), "se apropriadamente empregada, ajuda a determinar os aspectos efetivos e valorativos das respostas dos entrevistados e a determinar o significado pessoal de suas atitudes". Elaborou-se o roteiro de entrevistas a partir do referencial teórico adotado e das questões relevantes para a investigação. As entrevistas foram realizadas com os cinco grupos já elucidados. 
A investigação foi aprofundada com a formação de um grupo focal, constituído por dois representantes de cada grupo de mobilização, com a finalidade de utilizar as características do grupo focal, quais sejam: possibilidades de intervenção em tempo real, no curso da análise, e confrontação das percepções de participantes, em suas similitudes e contradições, a respeito do grupo de temas relacionados com o objetivo da pesquisa (RUEDIGER e RICCIO, 2004).

Foram conduzidas mais três entrevistas em profundidade, com integrantes da cúpula gerencial, com a finalidade de consolidar as informações obtidas anteriormente. Como segunda fonte de evidência optouse por analisar documentos da organização. Esses documentos incluíram relatórios de formulação da Visão de Futuro, Missão, Declaração de Valores e Planejamento Estratégico.

A análise dos resultados das entrevistas foi feita utilizando-se a técnica de análise do conteúdo (BARDIN, 1977), admitindo-se que ela, em geral, é utilizada em pesquisas exploratórias (VERGARA, 2005).

\section{Apresentação e Análise dos Resultados}

Com base em Bardin (1977), a análise de conteúdo das entrevistas e do grupo focal obedeceu à seguinte seqüência: No momento da pré-análise, foi feita uma leitura flutuante do material compilado e selecionados os dados com base na característica que exige informações adequadas ao estudo e aos seus objetivos. Em seguida, com base na exploração do material, foi feita a execução do planejamento elaborado na pré-análise, de modo consistente com os objetivos.

A codificação foi feita agregando-se os conteúdos das entrevistas e do grupo focal que pudessem ser classificados sob um mesmo tema. Posteriormente organizou-se por semelhanças. Após a sistematização considerou-se pertinente estabelecer, a partir dos dados coletados, as três categorias que serviriam de bases de estrutura da análise, com vistas a ordenar e coordenar as informações coletadas, quais sejam: forma de gestão, necessidade de mudar e estratégia re-educativa.

Como primeira base de dados desta pesquisa, realizada por meio da análise documental, têm-se o levantamento inicial, realizado pela alta direção da subsidiária, o qual trouxe à tona quatro incidentes críticos: perda de market share de 70\% para 50\%; aumento do índice de refugos em todos os produtos, de $23 \%$ para $50 \%$; incremento da insatisfação dos gerenciados e aumento de $48 \%$ para $71 \%$ do número de registros de atos inseguros, incidentes e acidentes de trabalho. Tal levantamento culminou com a necessidade declarada, pelos envolvidos, de fazer mudanças no estilo de gestão. Evidencia-se, então, o ponto de partida para o reconhecimento da necessidade de 'o quê' mudar. O 'porquê' da necessidade de mudança foi respondido pelos relatos de alguns gestores e uma análise inicial dos elementos da cultura organizacional, principalmente dos artefatos e estilo de comunicação, os quais apontavam que o controle coercitivo estava diminuindo o comprometimento e reduzindo a participação, aumentando a insatisfação interna e comprometendo a satisfação do cliente e a competitividade da organização.

Com o propósito de iniciar um diálogo teórico-empírico, relembre-se a concepção de Chaves, Santos e Morais (2004), na qual 'o porquê' mudar pode ser classificado em reativo ou voluntário, 'o como mudar' em re-educativo ou coercitivo e 'o que mudar' em incremental ou revolucionário. Observe-se que, inicialmente, se pôde observar um 'por que' reativo, em razão dos incidentes e da confrontação dos paradigmas culturais vigentes. $\mathrm{O}$ 'como mudar' pode ser considerado como re-educativo, de acordo com o que se segue.

Os grupos prosseguiram com o objetivo de identificar os fatores impulsionadores e restritivos das suas práticas atuais de gestão e a sua associação com os incidentes críticos. O processo adotado para intervenção, ou seja, 'como mudar', seguiu a orientação do modelo teórico proposto por Fischer (2002), conforme explicitado na seção anterior, e desenvolveu-se por meio das etapas de auscultação, concepção, 
disseminação / adesão e sustentação. Essa sistematização apresentou a oportunidade de analisar criticamente o processo.

A apresentação dessa análise crítica também seguirá, aqui, a seqüência desse modelo. Reforce-se que, apesar de seqüenciais, as suas etapas não se apresentam de forma estanque, relacionando-se de modo interdependente.

Como caracterização da etapa de auscultação, foram iniciados mapeamento sobre os cargos existentes e as suas atribuições, resgate do histórico da empresa e análise da documentação dos incidentes críticos. Houve um consenso, na declaração dos envolvidos, de que as suas ações deveriam se orientar pelos valores proclamados - compromisso e aprendizagem conjunta. Por meio de tal declaração, evidenciou-se abertura para mudança do modelo mental vigente, antes orientado apenas para os aspectos tangíveis do processo de trabalho.

Registre-se que eleger valores implica em mudar comportamentos. Por seu turno, comportamentos e relações mostram esses valores. A proclamação de valores, a partir dessa etapa, pôde representar apenas o desejo dos integrantes dos grupos de fazer com que essa mudança ocorresse.

O perfil de liderança do presidente CEO da empresa, engenheiro de formação, foi identificado como sendo de uma figura carismática e que conquistou sua posição fazendo uma carreira acelerada dentro da organização, na qual começou como técnico e alcançou a liderança com poucos anos de trabalho. Ressaltaram-se suas habilidades gerencial e técnica para tal conquista. Evidencie-se a relação da sua identidade pessoal e profissional com o paradigma organizacional vigente, da estabilidade.

A Figura 1 apresenta o organograma da empresa. Destaque-se que o maior contingente está subordinado ao diretor de produção. Como ordem de grandeza para todas as demais diretorias, cada gerente de primeira linha conta com gerentes de segunda linha, supervisores e auxiliares. Os gerentes de produção contam com supervisores, chefes de turma (noturnos / diurnos), operadores chefes, operadores e operadores auxiliares. Saliente-se, portanto, uma estrutura bastante hierarquizada.

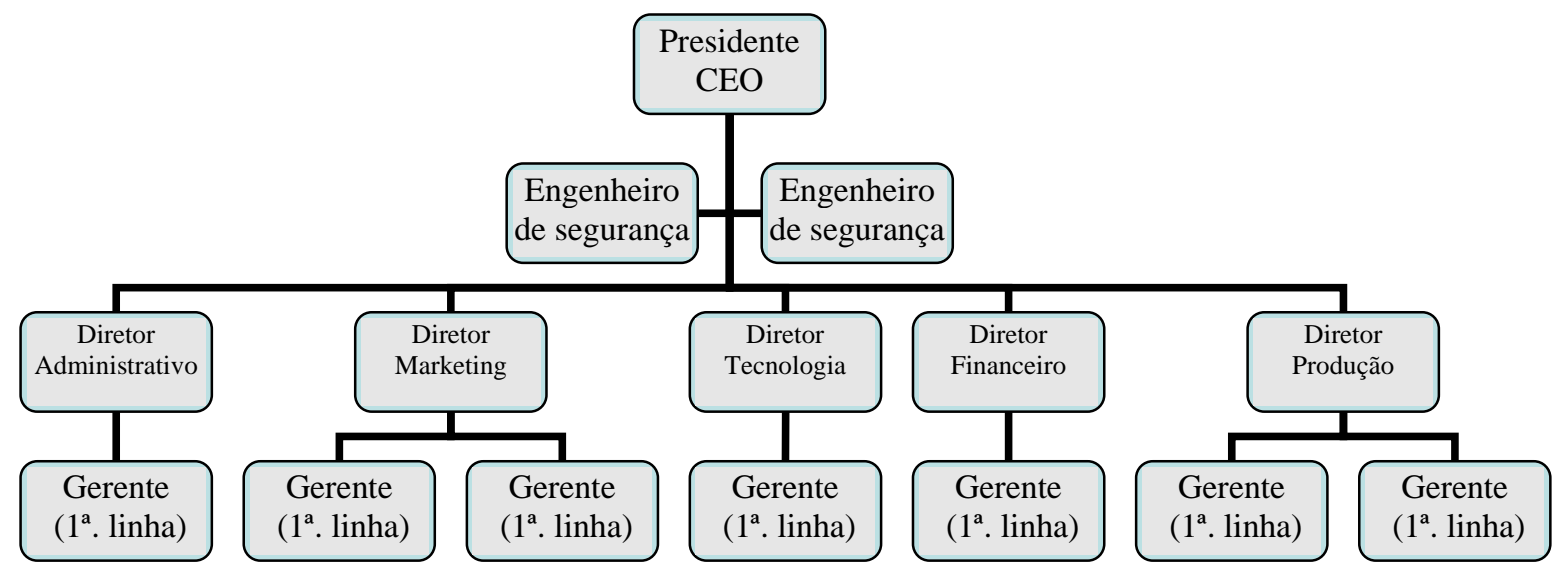

Figura 1 - Organograma da Empresa

Ainda na etapa de auscultação, por intermédio de questionário fechado, o grupo extrapolou os limites da organização e consultou, também, os seus fornecedores e clientes. Os dados obtidos dos clientes confirmaram que os problemas de qualidade levaram à perda de market share. Os obtidos dos 
fornecedores, por sua vez, não contribuíram de maneira expressiva para a identificação de pontos de melhoria.

Relembre-se que, na visão de autores como Fischer (2002) e Garvin (1998), a mudança é um dos processos organizacionais no qual está imbuída a idéia de continuidade, inerente, portanto, ao paradigma da transformação, podendo ser modelado e gerenciado.

Após a validação, pela alta direção, os incidentes críticos levantados foram trabalhados por todos os níveis hierárquicos, a partir do exercício do campo de forças de Kurt Lewin (o que impulsiona e o que restringe a ocorrência desses incidentes). Esse trabalho propôs-se a minimizar ou transformar as forças restritivas e manter as forças impulsoras. Sensibilizou a organização e facilitou a etapa de disseminação / adesão, com o envolvimento de todos os níveis hierárquicos, desde a alta direção até o "chão de fábrica". Complementarmente, voltando a lembrar Pettigrew (1989), o processo de mudança deve desenvolver a interação contínua e a regulação entre contexto (ambiente organizacional externo e interno), processo (ações, reações e interações) e conteúdo (estratégia e áreas específicas de mudança).

Enfatize-se que o autor sugere a articulação do processo de mudança, tanto da estratégia quanto da cultura organizacional, visando a buscar a interação desses três aspectos organizacionais e responder as questões 'o que mudar' (conteúdo), 'o por que mudar' (contexto) e 'o como mudar' (análise do processo). Na etapa da concepção, os envolvidos organizaram-se inicialmente em quatro grupos de mobilização para o processo de mudança. Estabeleceu-se uma liderança para cada grupo, responsável por convergir e captar as forças desencadeadas pela mudança.

As reuniões dos grupos de mobilização, segundo as opiniões expressas pelos integrantes, criavam ambiência para o envolvimento e comprometimento das pessoas. De início, cada grupo de mobilização ficou responsável por um dos quatro incidentes críticos, mas a observância da necessidade de buscar a interação entre contexto, processo e conteúdo, os levou à necessidade de mais um grupo de mobilização, estabelecido para tratar da instauração da confiança. Tal propósito foi eleito pelo grupo como um valor a ser desenvolvido como parte da cultura organizacional, conjuntamente com a abertura no processo de comunicação. Não obstante seu caráter intangível chegou-se ao entendimento de que a constatada dificuldade de obter essa confiança não poderia constituir-se em impedimento para monitorar as ações capazes de ajudar a construí-la.

Esse grupo estabelecido para tratar da instauração da confiança foi composto por doze engenheiros supervisores de áreas, sob liderança do presidente CEO e do diretor administrativo. Teve como papéis, ditos fundamentais, dar condições e reforçar a necessidade de comunicação aberta. A Figura 2 ilustra a dinâmica criada pelos grupos após as suas reflexões iniciais. 


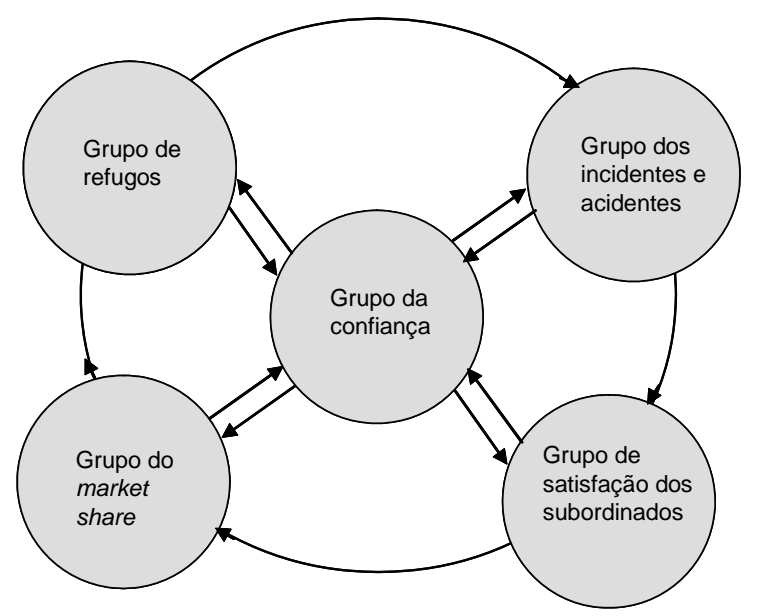

Figura 2 - Grupos de Mobilização

O grupo de refugos, integrado pelo diretor de produção, gerentes de todas as áreas e mais o diretor de marketing, foi responsável por detalhar os projetos de aperfeiçoamento do mapeamento inicial. Com ajuda do grupo de confiança, chegou-se a identificar formas de sabotagem que levavam ao aumento do número de refugos. Foi estabelecida a meta de reduzir o índice desses refugos de 50\% para 2\%.

Para lidar com incidentes e acidentes, o grupo correspondente ficou, então, composto pelos dois engenheiros de segurança da empresa, vinte e sete acidentados que haviam iniciado um trabalho voluntário com vistas à redução de atos inseguros, incidentes e acidentes, mais o diretor financeiro. A inserção desse diretor tinha o caráter de facilitar o orçamento e a liberação das verbas necessárias às ações identificáveis como necessárias. Contando com o auxílio do grupo de confiança, foram identificadas formas utilizadas pelos funcionários para esconderem os incidentes, por receio de perdas de premiação e, até mesmo, casos de acidentados que não procuravam atendimento médico por receio de punição. O grupo estabeleceu como meta “zerar” (sic) o número de afastamentos que, há algum tempo, era constituído de um por semana.

O grupo de market share formado, com exceção do diretor, por toda a equipe de marketing, em função do conhecimento dos clientes, e um gerente de cada área, justificados em razão da interdisciplinaridade, estabeleceu como meta a recuperação dos $20 \%$ de market share perdidos dos originais $70 \%$ de mercado. No que tange à satisfação dos subordinados, o grupo era formado por gerentes de segunda linha, mais o diretor administrativo e o médico do trabalho, esse último escolhido pelo histórico de ouvidor de uma série de descontentamentos "delatados e relatados" (sic) no ambiente de atendimento médico, na fase em que a área de recursos humanos ainda não havia sido instituída. A meta combinada pelo grupo foi a de aumentar a comunicação entre chefes e subordinados.

Com os valores proclamados, confiança, compromisso e validação, a etapa de disseminação e adesão foi facilitada pela auscultação com relação aos incidentes críticos. Foram promovidos encontros de feedbacks, a cada quinze dias, durante todo o processo, entre todos os envolvidos nos grupos de mobilização. A adesão foi trabalhada com base na atuação do presidente CEO e na liderança pelo exemplo do diretor de produção. Cafés da manhã foram programados e realizados nessa etapa.

A etapa de sustentação, na qual foram reunidos os valores proclamados nas etapas anteriores, consistiu do acompanhamento de cada líder de grupo, dos mapas relacionados a cada incidente crítico e discussão entre todos os líderes acerca de todos os incidentes. O grupo de refugos conseguiu reduzir de 50\% para 5\%, 
muito próximo da meta de $2 \%$. O grupo de market share conseguiu recuperar $11 \%$ dos $20 \%$ intencionados.

O grupo de incidentes e acidentes reduziu a zero o número de afastamentos no quarto mês do início das ações, o que foi atribuído ao trabalho anterior do grupo voluntário para a redução de acidentes.

Questionados durante o período inicial do processo sobre o possível excesso de reuniões, os dirigentes afirmaram que, por meio da participação dos grupos de mobilização, os avanços tornavam-se muito mais produtivos e eficazes do que o trabalho isolado e de aparente produtividade, executado anteriormente dentro do departamento. Mostrava-se claro o direcionamento estratégico nesses momentos.

Reenfatize-se que Fischer (2002) assume como um pressuposto para a mudança, duas engrenagens: a do direcionamento estratégico (por que mudar) e a da configuração organizacional (o que mudar) traduzidas no sistema de gestão da organização. No que tange ao processo de transformação organizacional (como mudar) a autora define que ele deve ser ancorado pelos parâmetros de abrangência, integração e sustentação.

Foram assumidos pela alta direção e validado pelos envolvidos no grupo focal seis pressupostos teóricos, os quais foram expressos em suas falas e que norteariam todo esse processo de mudança. O Quadro 2 mostra a análise do conteúdo das entrevistas e do grupo focal, a partir das categorias encontradas, bem como desses pressupostos assumidos e validados.

Com um dos pressupostos teóricos assumidos neste trabalho, "uma forte cultura pressupõe o comprometimento dos empregados com os objetivos organizacionais” (FLEURY e FLEURY, 1997), pode-se sugerir que a gestão da mudança dos padrões culturais dessa organização necessariamente parte do comprometimento dos grupos de mobilização com todas as etapas do processo.

Com o outro pressuposto, "o alinhamento entre as declarações da empresa e o comportamento gerencial é a chave para a construção de um contexto que promova o comprometimento dos empregados na dimensão social” (STREBEL, 1999), pode-se indicar que, conseqüentemente, os empregados tenderão a perceber essa dimensão social.

Percebe-se nessa análise o alinhamento com Moscovicci (1994), quando alerta para a importância dos objetivos claramente compartilhados, da comunicação verdadeira, da confiança e do respeito, da cooperação e da ajuda como bases de investimento constante da organização em prol do seu próprio crescimento e da sua sinergia. Entretanto, não se pode afirmar que houve a vitalização dos comportamentos para fazer a transição do padrão de estabilidade para o de transformação.

\begin{tabular}{|c|c|c|}
\hline $\begin{array}{l}\text { Categorias } \\
\text { Encontradas }\end{array}$ & $\begin{array}{l}\text { Pressupostos Teóricos } \\
\text { Assumidos no Processo }\end{array}$ & Depoimentos que os Confirmam \\
\hline Forma de Gestão & $\begin{array}{l}\text { A atribuição fundamental da liderança é lidar } \\
\text { com a dinâmica da mudança e com a confluência } \\
\text { e congruência das forças desencadeadas pela } \\
\text { mudança; } \\
\text { A cultura da organização deve ser fundamentada } \\
\text { na valorização do ser humano, de seu trabalho, da } \\
\text { inteligência que cada indivíduo aplica nesse } \\
\text { trabalho e na geração de conhecimento } \\
\text { organizacional advinda da inter-relação pessoa / } \\
\text { saber / organização. }\end{array}$ & $\begin{array}{l}\text { "Como líderes, precisaremos aprender sobre o } \\
\text { que nos dizem os incidentes e, sobretudo, } \\
\text { como nos uniremos para debelarmos nossos } \\
\text { problemas"; } \\
\text { "Baseados nos incidentes, trabalharemos com } \\
\text { os ouvidos abertos para o que as pessoas que } \\
\text { executam têm a nos dizer no seu dia-a-dia”. }\end{array}$ \\
\hline & $\begin{array}{l}\text { A transformação organizacional só se efetiva com } \\
\text { as pessoas, para as pessoas e por intermédio do } \\
\text { envolvimento e comprometimento das pessoas; }\end{array}$ & $\begin{array}{l}\text { "É de vital importância nos colocarmos abertos } \\
\text { para que as pessoas em nossa organização } \\
\text { possam nos dizer como melhorarmos a }\end{array}$ \\
\hline
\end{tabular}




\begin{tabular}{|c|c|c|}
\hline $\begin{array}{l}\text { Necessidade de } \\
\text { Mudar }\end{array}$ & $\begin{array}{l}\text { É requisito essencial o estabelecimento da } \\
\text { conexão entre estratégia e transformação. }\end{array}$ & $\begin{array}{l}\text { situação, independente de que posição elas } \\
\text { ocupem”; } \\
\text { “A partir desses incidentes críticos podemos } \\
\text { estabelecer como princípio, que o problema de } \\
\text { uma área passa a ser problema de todas as } \\
\text { áreas” }\end{array}$ \\
\hline $\begin{array}{l}\text { Estratégia Re- } \\
\text { educativa }\end{array}$ & $\begin{array}{l}\text { Um dos paradoxos da mudança é a constatação de } \\
\text { que a confiança é tão necessária quanto difícil de } \\
\text { ser conquistada. } \\
\text { A modelagem e o gerenciamento do processo de } \\
\text { transformação exigem instrumentos que } \\
\text { assegurem sua internalização nas esferas mais } \\
\text { íntimas da organização. } \\
\text { A transformação constitui-se em um processo } \\
\text { contínuo de construção e reconstrução do } \\
\text { significado da organização. }\end{array}$ & $\begin{array}{l}\text { "As reais razões para o incidente ligado à } \\
\text { segurança nos falam da confiança que não } \\
\text { estamos sendo capazes de inspirar. Caramba! } \\
\text { Sem ela, como caminharemos?” } \\
\text { "Levaremos o campo de forças, por nós } \\
\text { levantado, a todos os escalões de nossa } \\
\text { organização" } \\
\text { "Precisamos deixar de lado os nossos apegos e } \\
\text { começarmos do zero se assim for preciso". }\end{array}$ \\
\hline & $\begin{array}{r}\text { Quadro 2 - Análise de Conteúd } \\
\text { Fonte: elaborado pelas autoras a partir dos }\end{array}$ & $\begin{array}{l}\text { do Caso } \\
\text { dados da pesquisa }\end{array}$ \\
\hline
\end{tabular}

\section{Considerações Finais}

Este trabalho, cujo primordial objetivo foi o de apontar como gerir os processos de mudança de uma organização, do paradigma da estabilidade para o da transformação, facilitou a elucidação de alguns pontos fundamentais na gestão da mudança de padrões, a iniciar pela compreensão prática da inadequação dos pressupostos que envolvem o paradigma da estabilidade, compreensão essa tomada como força impulsora para a busca da implementação do paradigma da transformação organizacional.

No que tange aos fatores que facilitam ou dificultam a gestão da mudança dos padrões culturais de uma organização, observou-se, com base na literatura consultada e nos apanhados empíricos, a dificuldade está implícita no próprio processo de transformação organizacional.

Tomando-se por base os pressupostos teóricos assumidos neste trabalho, quais sejam: muitas organizações têm caráter não-linear e encaram a estabilidade como nociva à evolução; as mudanças são, necessariamente, acompanhadas por quebras de paradigmas; mudança organizacional engloba alterações fundamentais no comportamento humano, nos padrões de trabalho e nos valores; a mudança ocorre em resposta a modificações ou antecipações estratégicas, tecnológicas ou de recursos, bem como o diálogo teórico/empírico nele travado, pode-se depreender que o processo de transformação ocorre, nessa organização, mediante pressupostos básicos claramente detectados nas falas dos entrevistados, consubstanciadas com a realização do grupo focal.

Retomando-se o objetivo de caracterizar o ambiente interno da organização, é factível indicar que sua transformação só se tornou possível a partir dos desejos mais profundos e conscientes dos seus integrantes, na medida em que ela reforçou, concomitantemente, as necessidades de: abertura; colaboração e ajuda; efetividade para a solução dos problemas oriundos dos incidentes críticos detectados; comprometimento com a melhoria dos resultados da organização; transformações na organização humana do trabalho; exercício sistemático de feedback; incremento do nível de confiança.

Em decorrência, o tratamento dado aos incidentes críticos detectados fez com que a organização voltasse sua atenção para um direcionamento estratégico que buscasse investigar o seu posicionamento no 
mercado, os resultados alcançados, suas práticas de gestão de pessoas, seu sistema de comunicação vertical e horizontal e suas práticas de gestão da produção.

A busca da excelência de gestão, na organização Alfa, tornou possível este estudo, por razões como: já havia o reconhecimento da necessidade de revisão dos padrões culturais; a disposição para conceber e gerir o processo de mudança estava clara, entre os gestores; esse seu processo já vinha sendo desenhado internamente há dois anos, em linha com o paradigma da transformação.

A etapa de concepção, entretanto, apresentou-se com falhas de processo, a saber: a composição mais homogênea do grupo de mobilização para o incidente crítico market share reforçou a possibilidade de 'feudalização', uma vez que a homogeneização aumenta o saber do grupo; a criação de um grupo de confiança, não obstante a indicação de interdependência com os outros quatro grupos, sugere, pela natureza intangível, a ação de privilegiar o pensar, em contraposição com as ações técnico-operacionais caracterizadas pelo caráter tangível das atividades dos demais grupos.

Com relação à questão ‘o que mudar’, pode-se entender que ela está entrelaçada com a dimensão objeto da mudança, por afetar toda a organização e atingir dimensões como missão, princípios de atuação, valores dominantes, normas e mercados. Nessa dimensão, dois pontos chamaram a atenção: as soluções dos problemas originados pelos quatro incidentes críticos passaram a ser oriundas das discussões entre todas as áreas; a conquista da confiança passou a ser a força-tarefa mais emergente, não obstante sua intangibilidade. $\mathrm{O}$ 'por que mudar' aos poucos se foi delineando em transição do reativo para o voluntário, 'o como mudar' em re-educativo, e 'o que mudar' tendendo ao revolucionário. É possível dizer que como gerir o processo de mudança dos padrões culturais da organização Alfa encontra resposta no próprio processo estratégico de transformação, considerando-se conteúdo, contexto e processo.

Uma das limitações deste estudo diz respeito à etapa de auscultação, estruturada tendo em vista os incidentes críticos inicialmente apresentados pela Direção. O processo de intervenção também ficou restrito às áreas diretamente envolvidas com os problemas levantados. Entende-se que uma ampliação deste trabalho inicial faz-se necessária como meio de viabilizar um processo de transformação que chegue à etapa de sustentação, como propõe o modelo.

\section{Referências}

ABBAGNANO, N. Dicionário de Filosofia, São Paulo: Martins Fontes, 2003.

ADIZES, I. Gerenciando as Mudanças: O poder da confiança e do respeito mútuos, São Paulo: Livraria Pioneira Editora, 1991.

AKTOUF, O. O simbolismo e a Cultura de Empresas: dos abusos conceituais às lições empíricas, (Tradução de Maria Helena Trylinski) In: CHANLAT, Jean-François. O Indivíduo na Organização: Dimensões Esquecidas, São Paulo: Atlas, Volume II, p. 40-78, 2001.

AMADO, G.; FAUCHEUX, C; LAURENT. A. Mudança Organizacional e Realidades Culturais: contrastes Franco-Americanos (Tradução de Cláudia Maria Contin). In: CHANLAT, Jean-François. O Indivíduo na Organização: Dimensões Esquecidas. São Paulo: Atlas, Volume II, p. 123-158, 2001.

BARDIN, L. Análise de Conteúdo. Lisboa: Edições 70, 1977.

BUSCAGLIA, L. Amor. Rio de Janeiro: Editora Record, 1994. 
CHANLAT, J-F. Por uma Antropologia na Condição Humana nas Organizações (Tradução de Ofélia de Lanna Sette Tôrres) In: CHANLAT, Jean-François O Indivíduo na Organização: Dimensões Esquecidas. São Paulo: Atlas, Volume II, p. 21-45, 1996.

CHAVES, A. M.; SANTOS, M. V.; MORAIS, J. H. M. Representação Social da Mudança Organizacional: Estudo de Caso Numa Empresa Petroquímica de Salvador. In: Revista Psicologia: Organizações e Trabalho, Trindade: UFSC, v.4, n.2, p. 63-84, 2004.

DUPUIS, J. P. Antropologia, Cultura e Organização: proposta de um modelo construtivista, (Tradução de Maria Helena Trylinski), In: CHANLAT, Jean-François O Indivíduo na Organização: Dimensões Esquecidas. São Paulo: Atlas, Volume II, p. 231-251, 1996.

DAMÁSIO, A. R. O Erro de Descartes - Emoção, Razão e Cérebro Humano. São Paulo: Companhia das Letras, 1996.

DUCK, J. D. Gerenciando a Mudança - A Arte do Equilíbrio. In: Harvard Business Review. Mudança. Rio de Janeiro: Editora Campus, p. 56 - 79, 1999.

FLEURY, M.T. L.; SAMPAIO, J. R. Uma Discussão Sobre Cultura Organizacional. In: FLEURY, M.T. L. (Org.) As Pessoas na Organização. São Paulo: Editora Gente, p. 283 -294, 2002.

FISCHER, R. M. Mudança e Transformação Organizacional. In: FLEURY, M.T.L. (Org.). As Pessoas na Organização. São Paulo: Ed. Gente, p. 259 - 269, 2002.

GARVIN, D. A. The Process of Organization and Management. Sloan Management Review. Summer, v. 39, n. 4, p.33-50, 1998.

HELLIWELL, T. Trabalhando com Alma. São Paulo: Editora Cultrix, 2002.

HERZOG, J. P. People: The Critical Factor in Managing Change. Journal of Systems Managing. Cleveland, v.42, nº3, Mar., p. 6-11, 1991.

HUEY, J. Nothing is Impossible (Paradigm Shifting). New York: Fortune, v.124, n ${ }^{0}$ 7, Sept, p.90-94, 1991.

KIEL, L. D. Nonequilibrium Theory and its Implications for Public Administration. Public Administration Review. Washington, v. 49, Nov/Dec., nº 6, p.544-551,1989.

KOTTER, J. P. Liderando a Mudança - Por que fracassam as tentativas de transformação. In: Harvard Business Review, Mudança, Rio de Janeiro: Editora Campus, p. 9 - 26, 1999.

MARTIN, R. Mudando a Mentalidade da Empresa. In: Harvard Business Review. Mudança. Rio de Janeiro: Campus, p. 108 - 131, 1999.

MORGAN, G. Imagens da Organização. São Paulo: Editora Atlas, 1996.

MOSCOVICI, F. Equipes Dão Certo. Rio de Janeiro: José Olympio Editora, 1994.

PETTIGREW, A. M. A Cultura das Organizações é Administrável?, In: FLEURY, M. T. L.; FISCHER, R. M. Cultura e Poder nas Organizações. São Paulo: Editora Atlas, p.145-153, 1989. 
RICHARDSON, R. Pesquisa Social: Métodos e Técnicas. São Paulo: Ed. Atlas, 1989.

ROGERS, C. R. Sobre o Poder Pessoal. São Paulo: Livraria Martins Fontes Editora Ltda., 1977.

RUEDGER, M.A.; RICCIO, V. Grupo Focal: Método e Análise Simbólica da Organização e Sociedade. In: VIEIRA, M. M. F.; ZOUAIN, D. M. Pesquisa Qualitativa em Administração, Rio de Janeiro, Editora FGV, 2004.

SCHAFFER, R. H.; THOMSON, H. A. Os Programas de Mudança Bem-Sucedidos começam com Resultados. In: Harvard Business Review, Mudança. Rio de Janeiro: Campus, p.175-79, 1999.

SCHEIN, E. H. Organizational Culture and Leadership. São Francisco: Jossey-Bass, 1985.

SELLTIZ, C.; WRIGHTSMAN, L.S.; COOK, S.W. Métodos de Pesquisa nas Relações Sociais, Vol. 2, Medidas na Pesquisa Social. São Paulo: EPU, 2005.

SILVA, N.; ZANELLI, J. C. Cultura Organizacional. In: ZANELLI, J. C.; BORGES-ANDRADE, J. E., BASTOS, A. V. B. Psicologia, Organizações e Trabalho no Brasil. Porto Alegre: Artmed, p. 407-422., 2004.

STREBEL, P. Por que os Empregados Resistem à Mudança? In: Harvard Business Review, Mudança, Rio de Janeiro: Editora Campus, p. 132 - 148, 1999.

VASCONCELOS, F. C.; VASCONCELOS, I. F. G. (Org.) Paradoxos Organizacionais: Uma Visão Transformacional. São Paulo: Pioneira Thomson, 2004.

VERGARA, S. C. Métodos de Pesquisa em Administração. São Paulo: Editora Atlas, 2005.

WHEATLEY, M. J. Liderança e a Nova Ciência. São Paulo: Editora Cultrix, 1992.

YIN, R. Estudo de Caso: Planejamento e Métodos. São Paulo: Bookman, 2005. 